\title{
HISTORIA Y SIGNIFICADOS DE LAS EXPRESIONES CON GERUNDIO Y CON EN + GERUNDIO
}

\author{
THE HISTORY AND MEANINGS OF GERUND \\ AND EN + GERUND EXPRESSIONS
}

JAVIER Mora García

javier.mora@uva.es

Universidad de Valladolid

Fecha de Recepción: 15-03-2018

Fecha de Aceptación: 07-06-2018

RESUMEN:

Este trabajo profundiza en los valores que presenta el gerundio latino y el comportamiento de las expresiones con esta forma verbal con y sin la preposición en en castellano, prestando especial atención a sus usos con significado temporal de simultaneidad y a otros no temporales emanados de este, ya que han recibido escasa atención en la bibliografía. Este hecho se refleja en los estudios sobre la relación de simultaneidad, por lo que se propuso redefinir el concepto y elaborar una nueva clasificación de tipos y subtipos para que, sobre un corpus de elaboración propia, se encajasen los testimonios hallados en las diferentes categorías. Esta metodología evita confeccionar ejemplos ad hoc y permite trabajar con la información de textos reales.

PALABRAS CLAVE: gerundio, latín, castellano, simultaneidad, valores no temporales.

SUMMARY:

This work delves into the values which the Latin gerund has and the performances of expressions that use this verbal form with and without the preposition en in Spanish, pa- 
ying special attention to its uses with a temporal meaning of simultaneity and to other non-temporal ones which come from it because they have received little attention from the bibliography. This fact is reflected in simultaneity studies, so we have proposed to redefine this concept and develop a new classification of types and subtypes so that, based on a self-compiledthe testimonies found in the different categories could be fitted. This methodology avoids fabricating ad hoc examples and allows working with real texts.

KEYWORDS: gerund, Latin, Spanish, simultaneity, non-temporal values.

\section{INTRODUCCIÓN}

El gerundio es una forma verbal sobre la que, en general, se ha prestado escasa atención en la bibliografía, salvo De los Mozos (1973), Muñío (1995) y Sedano y Jiménez Juliá (2013), lo que motivó nuestro interés en su estudio. Aunque se ha explicado su origen en español desde el gerundio latino (Sedano y Jiménez Juliá 2013: 88-89), no se ha determinado en qué momento el participio de presente fue sustituido por el gerundio, lo que se convirtió en nuestra primera misión. La hipótesis que defendemos es que el siglo XV es el momento clave en el que disminuyen los casos de participio de presente y el gerundio se erige como la forma verbal predominante.

El repaso bibliográfico sobre en + gerundio determinó que existía mayor debate sobre la procedencia de esta construcción, por lo que, en segundo lugar, nos propusimos plantear una hipótesis sobre su origen. En nuestra opinión, defendemos que en español en + gerundio puede tener una triple procedencia: una herencia latina, un origen autóctono del romance peninsular y un contagio de la estructura franca en + participio de presente, que, por razones fonéticas, pudo interpretarse como gerundio.

En tercer lugar, la relación temporal de simultaneidad es la que menos atención ha recibido y no existe unanimidad ni en su definición ni en su clasificación, por lo que creemos que es necesario plantear una nueva hipótesis sobre este concepto y una nueva clasificación de sus tipos y subtipos.

En cuarto lugar, a excepción de Muñío (1995), los estudios sobre los valores temporales de simultaneidad del gerundio son también exiguos. Por este motivo, situamos los testimonios de gerundio y de en + gerundio en los diferentes tipos y subtipos de esta relación temporal. La hipótesis que defendemos es que el gerundio expresa más tipos de simultaneidad que $e n+$ gerundio.

Para llevar a cabo este estudio, elaboramos un corpus de elaboración propia, dado que los ejemplos utilizados en los estudios sincrónicos se basaban en testimonios aislados o confeccionados ad hoc y prescindían de la información de los textos reales. Para evitar este encorsetamiento, optamos por trabajar con dicho corpus, dado que, por un lado, enriquecen el estudio con datos sobre fechación, tipo de texto, competencia entre subordinantes o cuestiones como el prestigio, $y$, por otro, permiten que contemos con un número de ejemplos 
suficientemente considerable e importante para que tenga validez este estudio, puesto que de otro modo sería una labor inabarcable.

Para terminar, nos detuvimos en los valores no temporales del gerundio y de en + gerundio para intentar dilucidar cómo se llega a su expresión. A nuestro juicio, hay dos evoluciones semánticas tanto en el gerundio como en la expresión en + gerundio: por una parte, del ámbito de lo temporal se pasa a otros más abstractos, como los de causa, concesión y condición, y, por otra, del ámbito no temporal se pasa al instrumento y al modo.

La organización del artículo es, por tanto, la siguiente:

En primer lugar, explicaremos la procedencia del gerundio en español e intentaremos demostrar que desde el siglo IX se emplea el participio de presente y es el predominante, pero a partir del XV el gerundio se convierte en la forma más utilizada.

En segundo lugar, expondremos la definición y la clasificación de la relación temporal de simultaneidad que se encuentra en Mora García (2016).

En tercer lugar, mostraremos los tipos y subtipos de simultaneidad que expresa el gerundio y explicaremos la procedencia de los valores no temporales.

En cuarto lugar, intentaremos demostrar la hipótesis sobre el origen de la construcción $e n+$ gerundio en español y, al igual que en el gerundio, señalaremos sus valores temporales y no temporales.

Por último, expondremos las conclusiones de los puntos esenciales de este artículo.

\section{EL GERUNDIO. BREVE ESTADO DE LA CUESTIÓN}

No son muchas las obras que se han dedicado a esta forma verbal, entre las que destacan las de De los Mozos (1973), Muñío (1995) y, más recientemente, Sedano y Jiménez Juliá (2013). Para estos últimos el gerundio latino es "el resultado de la confluencia de dos formas que se utilizaban con fines parcialmente distintos en latín: el llamado desde Prisciano gerundium ('gerundio') y el participio de presente" (SEDANO y JIMÉNEZ JULIÁ, 2013: 88-89):

El GERUNDIO latino era un sustantivo verbal con significado activo que se empleaba para declinar el infinitivo. El gerundio carecía de nominativo, pues para este contenido ya se usaba el invariable infinitivo, con el cual el gerundio estaba en distribución complementaria [...]. La traducción habitual del gerundio latino es, bien con preposición más infinitivo, en el caso del acusativo [...] (ad legendum paratus, 'preparado para leer'), del genitivo [...] (modi essendi, 'modos de ser') o del dativo (aptus legendo, 'apto para leer'). En el caso del ablativo, usado a menudo para indicar instrumento o medio, su equivalencia en español suele ser con el gerundio (currendo domum adueni, 'llegué corriendo a casa').

El PARTICIPIO DE PRESENTE, forma no personal del infectum, tenía en el período clásico un acusado valor verbal cuando expresaba acciones, y expresaba un tiempo concomitante al del verbo principal: ( $\underline{\text { Cotta) }}$ pugnans occiditur ('Cota fue muerto en combate', i.e. 'mientras luchaba'); sin embargo, ya en latín arcaico y popular su valor nominal fue ganando terreno al verbal. 
El empleo predicativo del participio de presente desencadenó un cambio importante: "El valor nominal del participio de presente era fundamentalmente predicativo, como en vidi exeuntem mulierem ('vi a una mujer saliendo' lit. '... saliente') y será este uso el que desaparecerá de las lenguas romances, sustituyéndose por el gerundio" (SEDANO y JIMÉNEZ JULIÁ, 2013: 89). Como sintetizan Sedano y Jiménez Juliá (2013: 90), el proceso simplificador fue complejo: la forma resultante, procedente del ablativo del gerundio, conservó "el valor semántico común a ambas, esto es, su concomitancia con el valor del verbo principal o alguna otra referencia".

La oposición del gerundio y del participio de presente no fue lo suficientemente fuerte como para mantenerse en castellano, pero estos autores no especifican en qué momento se produjo la sustitución del participio de presente por el gerundio. Con objeto de hallar alguna pista, decidimos observar el comportamiento de la expresión regnante rege, con todas sus variantes gráficas, en textos notariales, que, a pesar de que tratarse de documentos formulaicos, arrojan luz sobre la cronología. Los datos del CORDE permiten observar un periodo de vigencia desde los siglos IX y X (1a-b) hasta el siglo XIII, concretamente hasta 1264 (1c). Nótese que rege se sustituye por el rey desde 1224 (2).

(1) a. Facta carta in era millessima octogesima prima, regnante rege Garsea in regnis suis (Anónimo, Fundación y dotación de la iglesia monasterial de Orbañanos, 8671043, CORDE)

b. Facta carta testamenti in die quod erit quinto kalendas Aprilis in era nongentesima quinquagesima prima, regnante rege Bermudo in Legione et comite Fernando Didaz in Lantarone (Anónimo, Donación de villas y propiedades de Lantarón a Santa María de Quijera, 913, CORDE)

c. regnante rege Alfonso con la reyna dona Violante, in Castella et Legione et in Andaluzia (Anónimo Carta de venta, 1264, CORDE)

(2) REGNANTE EL REY don Ferrando en uno con su mugier la reyna dona Beatriz en Burgos i en Toledo i en Castiella i en todo so regno (Anónimo, CARTA DE VENTA, 1224, CORDE)

Aunque el primer testimonio del gerundio en esta construcción se halla en un texto literario de 1251 (3a), el Calila e Dimna ${ }^{1}$, hay que tener en cuenta que este se ha conservado en una copia posterior. Lo importante es destacar que no comienza a utilizarse con cierta frecuencia hasta el siglo XV (3b).

(3) a. reinando el rey Sirechuel, que fue fijo de Cades, fue un omne a que dezían Berzebuey (Anónimo, Calila e Dimna, 1251, CORDE)

b. reinando el rey don Rodrigo [...], pasaron los alaraves en [E]spaña (Lope García de Salazar, Istoria de las bienandanzas e fortunas, 1471-1476, CORDE)

\footnotetext{
${ }^{1}$ Cacho Blecua y Jesús Lacarra (1988: 51-52 y 66) eligieron para su edición el manuscrito A, cuya "letra fue fechada por Gayangos como de finales del siglo XIV; en el catálogo de la biblioteca se anotaba, según C. Allen, "principios del XV", mientras que el P. Zarco lo fechó a mediados del XV". Incorporan del manuscrito B, del siglo XV, la introducción de al-Muqaffa` (89-98) y los capítulos XII (300-302 y XIII (303-304).
} 
Un hecho destacable, como se observa en la tabla 1 siguiente, es que reinante rege desaparece justo cuando empieza a utilizarse reinando el rey.

TABLA I

Participio de presente y gerundio de reinar en construcción absoluta (CORDE)

\begin{tabular}{|c|l|c|c|c|}
\hline SIGLOS & \multicolumn{1}{|c|}{ regnante rege } & reinante rege & reinante el rey/rei & reinando el rey \\
\hline IX & 1 caso en 1 documento & - & - & - \\
\hline X & 4 casos en 4 documentos & - & - & - \\
\hline XI & 60 casos en 60 documentos & -2 & - & - \\
\hline XII & 124 casos en 120 documentos & - & - & - \\
\hline XIII & 278 casos en 277 documentos & $\begin{array}{c}1 \text { caso en 1 } \\
\text { documento }\end{array}$ & $\begin{array}{c}1 \text { caso en 1 } \\
\text { documento }\end{array}$ & $\begin{array}{c}1 \text { caso en } 1 \\
\text { documento }\end{array}$ \\
\hline XIV & 2 casos en 2 documentos 4 & - & - & - \\
\hline XV & - & - & - & $\begin{array}{c}11 \text { casos en } 3 \\
\text { documentos }\end{array}$ \\
\hline XVI & - & - & - & $\begin{array}{c}10 \text { casos en } 8 \\
\text { documentos }\end{array}$ \\
\hline
\end{tabular}

Si comparamos estos datos con los de su empleo fuera de esta construcción, observamos que las fechas prácticamente coinciden (tabla 2).

${ }^{2}$ Se aprecia un testimonio de Reinante Reye: "Facta carta sub era M.LXXVIII. II Nonas Februarii feria VI. Reinante Reye Garcia in Pampilona" (Anónimo, Juicio sobre la libertad de una vecina de Terrero [Documentos relativos a los fueros municipales], 1040).

${ }^{3}$ Existe un caso de Rregnante el rrey en este siglo: "Rregnante el rrey don Alfonsso con sua muyer, ela reyna donna Uiolanda, en Leon ye en Toledo ye Cordoua ye en Siuilia. Martin Fferrandez, pela gracia de Deus, obispo en Leon" (Anónimo, Documento de venta [Documentos de la catedral de León], 1259).

${ }^{4}$ En esta centuria se halla un nuevo ejemplo de rregnante el rey: "E después desto, en el anno de la era de mille e trezientos e noventa e quatro annos, rregnante el rrey don Pedro, fijo del muy noble rrey don Alfonso" Anónimo, Fuero viejo de Castilla, 1356). 
TABLA 2

Participio y gerundio de reinar en uso libre (CORDE)

\begin{tabular}{|c|c|c|c|}
\hline SIGLOS & (r)regnante & reinante & reinando \\
\hline XIII & $\begin{array}{c}202 \text { casos en } \\
198 \text { documentos }\end{array}$ & 2 casos en 2 documentos & 2 casos en 2 documentos \\
\hline XIV & $\begin{array}{c}98 \text { casos en } \\
56 \text { documentos }\end{array}$ & - & 1 caso en 1 documento \\
\hline XV & $\begin{array}{c}19 \text { casos en } \\
11 \text { documentos }\end{array}$ & - & $\begin{array}{c}104 \text { casos en } \\
10 \text { documentos }\end{array}$ \\
\hline XVI & - & 1 caso en 1 documento & $\begin{array}{c}109 \text { casos en } \\
64 \text { documentos }\end{array}$ \\
\hline
\end{tabular}

No hay mucha diferencia entre los resultados de ambas tablas. Lo que más llama la atención es, por un lado, que el participio de presente no se halla, como esperaríamos, en los textos castellanos del siglo XV, centuria en la que el gerundio aumenta considerablemente su presencia, y, por otro, que en el XVI hay un testimonio aislado de reinante en la Historia general de las cosas de la Nueva España de Fray Bernardino de Sahagún, misionero franciscano que escribió obras en náhualt, castellano y latín, por lo que puede considerarse un uso latinista.

Las formas de participio de presente dejaron de expresar acciones y se quedaron con la función de adjetivo (ausente) o de sustantivo (cliente) (BASSOLS, 1987: §387). Una vez asentado el gerundio, entre los valores que puede expresar se encuentra el temporal: "solamente lo hace en el acto de habla cuando entra en relación con otro verbo y referido siempre a la acción indicada por ese verbo" (MUÑíO, 1995: 91-93), como muestran las paráfrasis "con a la vez que, mientras y otras partículas temporales similares", como en Salió dando un portazo o en Bajando las escaleras, me di cuenta de que se me había olvidado la cartera. (RAE-ASALE, 2009: §27.4c).

Dado que nos centraremos en el gerundio de simultaneidad, en el siguiente epígrafe nos detendremos en esta relación temporal y en sus tipos.

\section{LA SIMULTANEIDAD}

La simultaneidad es la relación temporal que, frente a la anterioridad y la posterioridad, menos atención ha recibido y sobre la que no existe unanimidad ni en su definición ni en su clasificación. Por esta razón, creemos que es necesario plantear un nuevo marco teórico que clarifique estos aspectos.

El caso del gerundio es aún más llamativo, ya que, como es sabido, es una forma verbal no personal que carecer de tiempo y que su aspecto es imperfectivo, dado que expresa una acción que está en desarrollo. Debido a estas características especiales, va a jugar un papel 
aún más importante la oración principal para establecer el tipo de simultaneidad del ejemplo en cuestión. Además, es interesante establecer la distinción entre gerundios periféricos y gerundios adjuntos porque favorecen la expresión de un valor u otro. Los primeros forman "cláusulas externas a la oración" y aparecen de manera habitual "al comienzo del período y separados por una pausa (Encaramándose sobre la silla, había conseguido alcanzar la mermelada), pero también se admiten en posición final de oración, con separación gráfica o prosódica [...] o en posición medial", mientras que los segundos "funcionan sintácticamente como modificador adjunto [...] Redactó el trabajo poniendo todo el cuidado del mundo" (RAE-ASALE, 2009: $\$ 27.11$ y $\$ 27.1 \tilde{n}$ ). Como se aprecia, en los ejemplos de los gerundios perifrásticos se favorece la expresión de la condición y de la causa, y en los segundos el significado modal.

Antes de centrarnos en el gerundio y en la construcción en + gerundio, nos centraremos en redefinir el concepto de simultaneidad y en establecer una nueva taxonomía.

No disponemos de un significado unívoco del término simultaneidad que facilite la clasificación de sus distintas expresiones, como se aprecia en la revisión de los estudios de referencia (EBERENZ 1982 y 2014, MÉNDEZ GARCÍA DE PAREDES 1995 y HERRERO

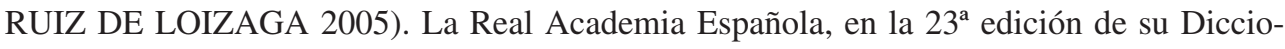
nario (2014: s.v. simultaneidad y simultáneo), se limita a decir: simultaneidad: "cualidad de simultáneo", y simultáneo, "dicho de una cosa: que se hace u ocurre al mismo tiempo". Por esta razón, creemos que es necesaria una definición más abarcadora para explicar el concepto y especificar sus características esenciales.

Antes de ofrecer nuestra propuesta, debemos especificar que no solo consideramos que las acciones pueden ser simultáneas, sino también los estados. La RAE (2014: s.v. estado), en su primera acepción, afirma que estado es una "situación en que se encuentra alguien o algo, y en especial cada uno de sus sucesivos modos de ser o estar". Por tanto, estos "sucesivos modos" implican duración, de tal forma que su vinculación con otra acción o estado que se produzca o se desarrolle al mismo tiempo también nos permite hablar de simultaneidad.

Hecha esta matización, para la definición de simultaneidad habría que tener en cuenta las siguientes puntualizaciones:

a. Las acciones o estados expresados en la oración principal y en la subordinada. Pueden ser ambos durativos, ambos puntuales o uno durativo y otro puntual.

b. Los sujetos que llevan a cabo tales acciones o manifiestan esos estados. Pueden ser uno o más.

c. El tiempo en el que transcurren esas acciones o estados. Pueden desarrollarse en un mismo lapso temporal o compartir, al menos, un segmento del tiempo que ocupa uno de ellos.

d. El lugar en el que transcurren las acciones o estados. Pueden producirse en una misma ubicación o en distintas.

e. La voluntariedad o no voluntariedad del sujeto de una de las acciones o estados o de ambos. 
Definimos la simultaneidad como la relación temporal mediante la cual dos o más acciones o estados durativos o puntuales, o uno durativo y otro puntual, son llevados a cabo o manifestados por uno o más sujetos, se desarrollan en un mismo lapso de tiempo o comparten, al menos, un segmento del tiempo que ocupa una de las acciones o estados; pueden suceder en un lugar compartido o en diferente ubicación y pueden realizarse con voluntariedad, sin ella, o uno de los estados o acciones con voluntariedad y el otro sin ella.

Según esta definición, la simultaneidad total es una relación temporal mediante la cual una o más acciones o estados durativos o puntuales son llevados a cabo o manifestados por un mismo sujeto o por dos distintos, se desarrollan en un mismo lapso de tiempo, pueden suceder en un lugar compartido o en distintas ubicaciones y pueden llevarse a cabo con voluntariedad o sin ella.

Para la definición de simultaneidad parcial, debemos precisar lo que entendemos por límite inicial, inclusión y límite final. Para realizar esta labor, optamos por seguir la clasificación de Carrasco (2011: 200-201), quien, cuando analiza la no puntualidad de los verbos de percepción, emplea la tipología de Schmiedtová (2004: 10) y sus esquemas. Schmiedtová habla de cuatro tipos de simultaneidad, aunque una de ellas no nos interesa en este momento: la simultaneidad total; las otras tres son: simultaneidad con el límite final (4a), simultaneidad con el límite inicial (4b) e inclusión (4c).

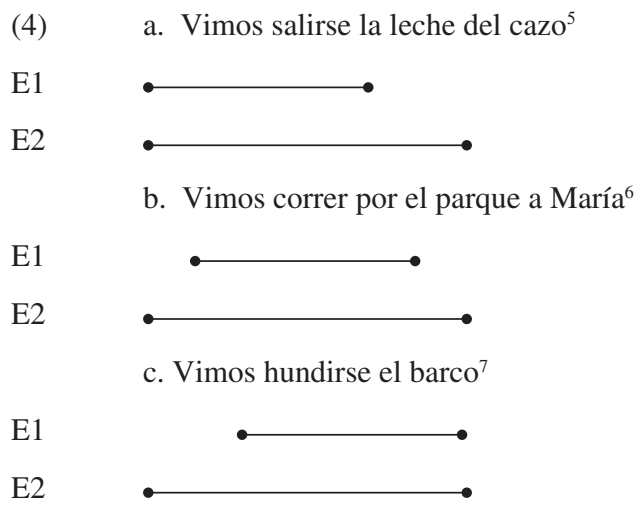

Como se puede apreciar en los tres ejemplos, las acciones de la subordinada y de la principal tienen distinta duración, pero coinciden durante un lapso de tiempo. Si este desarrollo paralelo se produce al principio, se habla de límite inicial (4a); si es durante su desarrollo, lo llamamos inclusión (4b); o si se produce al final, se denomina límite final (4c).

\footnotetext{
${ }^{5}$ El ejemplo completo sería Cuando nos asomamos a la puerta de la cocina, vimos salirse la leche del cazo (nos fuimos y esta siguió saliéndose).

${ }^{6}$ El ejemplo completo sería Mientras disfrutábamos de una mañana junto al estanque, vimos correr por el parque a María (estuvimos en el parque antes y después de ver pasar corriendo a María).

${ }^{7}$ El ejemplo completo sería Mientras estábamos en la última hora del paseo por el muelle, vimos hundirse el barco.
} 
Una vez realizado el intento de aclaración de este punto, podemos ofrecer una definición más precisa de simultaneidad parcial.

En nuestra opinión, la simultaneidad parcial es una relación temporal mediante la cual dos acciones o estados durativos o uno durativo y otro puntual comparten, al menos, un segmento del tiempo que ocupa una de las acciones o estados. La simultaneidad parcial puede producirse al principio (límite inicial), al final (límite final) o durante el desarrollo de la acción (inclusión). Pueden intervenir uno o más sujetos en un mismo lugar o en distinto, con voluntariedad o sin ella.

La cantidad de matices que se incluyen en la definición general de simultaneidad y en las de los dos tipos, simultaneidad total y simultaneidad parcial, obliga a elaborar una clasificación detallada de los distintos subtipos que permita incluir los distintos testimonios en el lugar que le corresponde.

Dentro de la simultaneidad total incluimos la sincronización durativa, la sincronización puntual, la coincidencia durativa, la coincidencia puntual, la concomitancia durativa y la concomitancia puntual.

Entendemos por sincronización una relación temporal mediante la cual dos o más acciones o estados durativos (5a) — sincronización durativa - o puntuales (5b) — sincronización puntual - iguales o distintos son llevados a cabo o manifestados por un mismo sujeto o por dos distintos, se desarrollan en un mismo lapso de tiempo, en un lugar compartido o en distintos lugares, siempre con voluntariedad.

(5) a. Mientras/cuando Juan está mirando por la ventana, se fuma un cigarrillo.

b. Cuando el malabarista tira una pelota roja con la mano derecha, lanza otra verde con la izquierda.

La coincidencia es una relación temporal mediante la cual dos o más acciones o estados durativos (6a) — coincidencia durativa - o puntuales (6b) — coincidencia puntualdistintos son llevados a cabo o manifestados por uno o más sujetos, se desarrollan en un mismo lapso de tiempo y en un mismo lugar, siempre sin voluntariedad.

(6) a. Mientras/cuando Laura asistía al taller de teatro, casualmente Juan se encontraba arreglando la calefacción de aquella misma sala.

b. Cuando María soltó el cuchillo, Juan se cortó.

Por último, la concomitancia es una relación temporal mediante la cual dos o más acciones o estados durativos (7a) — concomitancia durativa - o puntuales ( $7 \mathrm{~b})$ - concomitancia puntual-, iguales o distintos, son llevados a cabo o manifestados, siempre con voluntariedad, por uno o más sujetos, inciden o recaen sobre un mismo objeto y suceden en un mismo tiempo y en un mismo lugar. 
(7) a. Mientras/cuando Luis sujetaba el cuadro con la mano izquierda, lo limpiaba con la derecha.

b. Cuando Luis puso su mano izquierda sobre un hombro de Ana, a la vez le puso la derecha sobre el otro para empujarla.

En el siguiente cuadro resumimos los rasgos que presenta cada subtipo de simultaneidad total, cuya información está extraída de los cuadros generales que realizamos en Mora García (2016: 88-89).

TABLA 3

Rasgos de la simultaneidad total y de sus subtipos

\begin{tabular}{|c|c|c|}
\hline \multirow{3}{*}{$\begin{array}{l}\text { SIMULTANEIDAD TOTAL } \\
\text { - Un sujeto o más. } \\
\text { - Una o más acciones } \\
\text { durativas o puntuales. } \\
\text { - Uno o dos lugares. } \\
\text { - } \pm \text { Voluntariedad. }\end{array}$} & $\begin{array}{l}\text { SINCRONIZACIÓN } \\
\text { DURATIVA } \\
\text { — Un sujeto o más. } \\
\text { — Dos o más acciones o } \\
\text { estados durativos iguales o } \\
\text { distintos. } \\
\text { — Uno o dos lugares. } \\
\text { — + Voluntariedad. }\end{array}$ & $\begin{array}{l}\text { SINCRONIZACIÓN } \\
\text { PUNTUAL } \\
\text { - } \\
\text { Un sujeto o más. } \\
\text { - Dos o más acciones o } \\
\text { estados puntuales iguales o } \\
\text { distintos. } \\
\text { - } \text { Uno o dos lugares. } \\
\text { — + Voluntariedad. }\end{array}$ \\
\hline & $\begin{array}{c}\text { COINCIDENCIA } \\
\text { DURATIVA } \\
\text { - Un sujeto o más. } \\
\text { - } \text { Dos o más acciones o } \\
\text { estados durativos distintos. } \\
\text { - Uno o dos lugares. } \\
\text { - } \text {-Voluntariedad en la } \\
\text { subordinada o en la } \\
\text { principal, o en ambas. }\end{array}$ & $\begin{array}{l}\text { COINCIDENCIA } \\
\text { PUNTUAL } \\
\text { - Un sujeto o más. } \\
\text { - } \text { Dos o más acciones o } \\
\text { estados puntuales distintos. } \\
\text { - Uno o dos lugares. } \\
\text { - - Voluntariedad en la } \\
\text { subordinada o en la } \\
\text { principal, o en ambas. }\end{array}$ \\
\hline & $\begin{array}{l}\text { CONCOMITANCIA } \\
\text { DURATIVA } \\
\text { — Un sujeto o más. } \\
\text { — Dos o más acciones o } \\
\text { estados durativos iguales } \\
\text { o distintas realizados por } \\
\text { un sujeto o más sobre un } \\
\text { mismo objeto. } \\
\text { - Un mismo lugar. } \\
\text { — + Voluntariedad. }\end{array}$ & $\begin{array}{l}\text { CONCOMITANCIA } \\
\text { PUNTUAL } \\
\text { — Un sujeto o más. } \\
\text { — Dos o más acciones o } \\
\text { estados puntuales iguales } \\
\text { o distintos realizados por } \\
\text { un sujeto o más sobre un } \\
\text { mismo objeto. } \\
\text { - Un mismo lugar. } \\
\text { - + Voluntariedad. }\end{array}$ \\
\hline
\end{tabular}


En la simultaneidad parcial distinguimos cuatro tipos: simultaneidad parcial con más duración de la subordinada, simultaneidad parcial con más duración de la principal, coincidencia durativo-puntual y coincidencia puntual-durativa. En los dos primeros ninguno de los dos eventos implicados puede ser puntual, mientras que en los otros dos, al menos, uno de ellos debe serlo.

La simultaneidad parcial con más duración de la subordinada (8) puede considerarse como una relación temporal mediante la cual la acción o estado de la oración principal comparte un segmento del tiempo que ocupa la acción o estado de la subordinada, que es de mayor duración. La simultaneidad puede producirse al principio (límite inicial), al final (límite final) o durante su desarrollo (inclusión). Pueden intervenir uno o más sujetos en el mismo lugar o en distintos lugares, con voluntariedad o sin ella.

(8) Mientras/cuando Juan se encontraba trabajando en su tienda durante las horas finales de su jornada, María impartía una clase de Lengua de 50 minutos en la academia.

La simultaneidad parcial con más duración de la principal (9) presenta casi las mismas características que la anterior, con la única diferencia de que, en este caso, la principal ocupa un mayor tramo temporal.

(9) Mientras/ cuando Juan estaba comiendo el bocadillo entre las doce y las doce y media, la jornada de trabajo se desarrollaba sin incidencias.

Por su parte, la coincidencia durativo-puntual (10) es una relación temporal mediante la cual una acción o estado puntual expresado en la oración principal ocurre en un momento de la acción o estado durativo expresado por la subordinada. La coincidencia puede producirse al principio (límite inicial), durante su desarrollo (inclusión) o al final (límite final); pueden intervenir uno o más sujetos en el mismo o en distintos lugares, con voluntariedad o sin ella.

(10) Mientras/cuando estaba empezando la película, el teléfono sonó.

Como sucede con la simultaneidad parcial con más duración de la subordinada y la simultaneidad parcial con más duración de la principal, la coincidencia puntual-durativa (11) presenta casi los mismos rasgos que la coincidencia durativo-puntual, con la única diferencia de que la subordinada tiene aquí el matiz 'puntual' y la subordinada el 'durativo'.

(11) Cuando el teléfono sonó, estaba terminando la película.

En el siguiente cuadro resumimos, como en la simultaneidad total, los rasgos que presenta cada subtipo de simultaneidad total, cuya información está extraída de los cuadros generales que realizamos en Mora García (2016: 90-91). 
TABLA 4

Rasgos de la simultaneidad parcial y de sus subtipos

\begin{tabular}{|c|c|c|}
\hline $\begin{array}{l}\text { SIMULTANEIDAD } \\
\text { PARCIAL } \\
\text { — Un sujeto o más. } \\
\text { — Dos o más acciones } \\
\text { durativas, puntual-durativas } \\
\text { o durativo-puntuales. } \\
\text { - Las acciones no tienen } \\
\text { la misma duración, pero } \\
\text { se desarrollan en algún }\end{array}$ & $\begin{array}{l}\text { SIMULTANEIDAD } \\
\text { PARCIAL CON MÁS } \\
\text { DURACIÓN DE LA } \\
\text { SUBORDINADA } \\
\text { — Un sujeto o más. } \\
\text { — Dos acciones o estados } \\
\text { durativos; la subordinada } \\
\text { tiene más duración que la } \\
\text { principal. } \\
\text { - Uno o dos lugares. } \\
\text { — } \pm \text { Voluntariedad. } \\
\text { - Límite inicial, inclusión y } \\
\text { límite final. }\end{array}$ & $\begin{array}{l}\text { COINCIDENCIA } \\
\text { DURATIVO-PUNTUAL } \\
\text { — Un sujeto o más. } \\
\text { - Dos acciones o estados } \\
\text { durativos; la principal es } \\
\text { puntual y la subordinada es } \\
\text { durativa. } \\
\text { - Uno o dos lugares. } \\
\text { - } \\
\text { _Voluntariedad. } \\
\text { - Límite inicial, inclusión y } \\
\text { límite final. }\end{array}$ \\
\hline $\begin{array}{l}\text { momento de manera } \\
\text { paralela. } \\
\text { — El desarrollo paralelo } \\
\text { de tales acciones puede } \\
\text { producirse al principio } \\
\text { (límite inicial), durante su } \\
\text { desarrollo (inclusión) o al } \\
\text { final (límite final). } \\
\text { - Uno o dos lugares. } \\
\text { - } \\
\text { 土Voluntariedad. }\end{array}$ & $\begin{array}{l}\text { SIMULTANEIDAD } \\
\text { PARCIAL CON MÁS } \\
\text { DURACIÓN DE LA } \\
\text { PRINCIPAL } \\
\text { — Un sujeto o más. } \\
\text { — Dos acciones o estados } \\
\text { durativos; la principal } \\
\text { tiene más duración que la } \\
\text { subordinada. } \\
\text { — Uno o dos lugares. } \\
\text { — } \pm \text { Voluntariedad. } \\
\text { — Límite inicial, inclusión y } \\
\text { límite final. }\end{array}$ & $\begin{array}{l}\text { COINCIDENCIA } \\
\text { PUNTUAL-DURATIVA } \\
\text { - Un sujeto o más. } \\
\text { - Dos acciones o estados } \\
\text { durativos; la subordinada } \\
\text { es puntual y la principal es } \\
\text { durativa. } \\
\text { - Uno o dos lugares. } \\
\text { - } \\
\text {-Voluntariedad. } \\
\text { - Límite inicial, inclusión y } \\
\text { límite final. }\end{array}$ \\
\hline
\end{tabular}

Una vez sintetizados los puntos fundamentales de nuestra propuesta, nos centraremos en los significados temporales de simultaneidad y en los no temporales que muestran las expresiones con gerundio $(\S 3)$ y con $e n+$ gerundio $(\S 4)$.

\section{EL GERUNDIO}

En este apartado estudiaremos los valores temporales de simultaneidad del gerundio (§3.1) y los no temporales $(\$ 3.2)$. 


\subsection{El gerundio con significado temporal de 'simultaneidad'}

Apenas hay trabajos en los que se analicen los matices temporales de simultaneidad del gerundio español. Es una excepción Muñío (1995: 94), para quien las estructuras con gerundio que expresan "el tiempo durante el que se realiza la acción principal son [...] las más abundantes en los textos medievales españoles". Sin embargo, los datos que hemos extraído del corpus manejado indican que son mucho más frecuentes las estructuras encabezadas por cuando (hemos hallado 676 casos de cuando frente a 232 de gerundio durante la Edad Media, es decir, un 34,31\% más). Hecha esta salvedad, nos detendremos en otra de sus afirmaciones:

se pueden encontrar, por un lado, construcciones en que la de gerundio aparece simplemente como una acción secundaria simultánea a la principal durante todo el proceso, durante todo su desarrollo (concomitancia) y, por otro, otras en que la de gerundio quiere indicar con mayor concreción el momento, más o menos preciso, en que se realiza la acción principal (encuadre).

Este autor emplea el término concomitancia como sinónimo de simultaneidad total (12). En nuestra opinión, serían de sincronización durativa.

(12) a. E él dixo que viviendo con el rey de Granada, que el rey fiaba mucho dél (Don Juan Manuel, El Conde Lucanor, 1330-1335)

b. La señora de la villa estando con aquellos omes buenos non dizía ninguna cosa e estaua commo uergoñosa e enbargada (Anónimo, Libro del Caballero Zifar, 1300130)

Muñío $(1995,95)$ también ofrece ejemplos en los que "aun empleándose la construcción de gerundio para situar la acción principal, las dos acciones tienen lugar simultáneamente de manera puntual". En (13a) un mismo sujeto realiza, con voluntariedad en la subordinada y sin ella en la principal, dos acciones: una puntual, expresada por la principal, que se produce durante el desarrollo de la subordinada, y otra durativa, la subordinada. En (13b) dos sujetos llevan a cabo dos acciones puntuales iguales en una misma ubicación, en este caso con voluntariedad. Por tanto, en (13a) hablaríamos de coincidencia durativo-puntual y en (13b) de sincronización puntual, puesto que la hay.

(13) a. et entrando por una villa toparon con muy grand gente (Don Juan Manuel, El Conde Lucanor, 1330-1335)

b. E llegando el ynfante don Pedro a media legua de Sahagund, llego a el el ynfante don Felipe (Anónimo, Gran Crónica de Alfonso XI, c. 1348 - 1379)

Para este investigador (1995: 95), "lo más frecuente es que la proposición de gerundio indique una acción que se está desarrollando, y en un momento de ese proceso se produce, generalmente de manera puntual, la acción principal" (14a), valor recogido también por la Real Academia Española y la Asociación de Academias de la Lengua Española (2009: $\S 27.4 \mathrm{~d})$ (14b), lo que denominamos simultaneidad parcial, dado que se llevan a cabo dos 
acciones: una puntual, expresada por la principal, que se produce durante el desarrollo de la subordinada, y otra durativa, que es la subordinada: "la acción del gerundio desborda temporalmente por ambos lados, antes y después, a la del verbo principal" (MUÑíO, 1995: 95).

(14) a. Yo faziendo esto, ellos acabaron lo so (Anónimo, Cantar de Mío Cid, c. 1140)

Dixieron: nos dormiendo discípulos vinieron (Gonzalo de Berceo, Loores de Nuestra Señora, 1236-1246)

b. Buscando las lentes encontré la factura del dentista

Aunque estamos de acuerdo en los subtipos de simultaneidad de gerundio que plantea Muñío, creemos que existen más: sincronización durativa (15), sincronización puntual (16), coincidencia durativa (17), coincidencia puntual (18), concomitancia durativa (19), concomitancia puntual (20), simultaneidad parcial con más duración de la subordinada (21), coincidencia durativo-puntual (22-24) y simultaneidad parcial con más duración de la principal (25).

1. Sincronización durativa. Diferentes sujetos (15a) o uno solo (15b) realizan con voluntariedad dos acciones durativas distintas. Se suele decir que es la relación temporal más habitual en los gerundios.

(15) a. E él dixo que viviendo con el rey de Granada, que el rey fiaba mucho dél Don Juan Manuel, El Conde Lucanor, 1330-1335)

b. Ana, que se preparaba a una vida nueva, por dentro, cantaba alegre limpiando los estantes de la biblioteca en la quinta (Leopoldo Alas Clarín, La Regenta, 1884, 249)

2. Sincronización puntual. Dos sujetos (16a) o uno solo (16b) llevan a cabo con voluntariedad dos acciones puntuales distintas.

(16) a. e diz que durmiéndose él allí quel recibió Dios ell alma (Alfonso X, General Estoria. Primera Parte, c. 1275, 1082)

b. y llegando en su presencia, se apeó de su caballo (Pedro Mejía, Silva de Varia Lección, 1540, 97)

3. Coincidencia durativa. Un mismo sujeto (17a) — sin voluntariedad en la principal y con ella en la subordinada- o dos diferentes $(17 \mathrm{~b})$ — sin voluntariedad- realizan acciones o estados durativos distintos.

(17) a. E allí fallaron un campo tan llano e tan bueno e tan grand que estando en medio d'él que non podién devisar los cabos (Alfonso X, General Estoria. Primera Parte, c. $1275,50)$

pues de todo lo que en esta ciudad se hubo, siendo vivo Mutezuma (Hernán Cortés,

b. Cartas de Relación, 1526, 413) 
4. Coincidencia puntual. En (18a) la acción de la subordinada se lleva a cabo con voluntariedad y la de la principal sin ella, mientras que en (18b) un mismo sujeto realiza sin voluntariedad dos acciones puntuales distintas.

(18) a. e tornándose Abraham vío estar un cabrón apegado o preso en las matas (Alfonso X, General Estoria. Primera Parte, c. 1275, 197)

b. y tropezando en un barranco se desnucó (El Heraldo, 4/03/1852, 3)

5. Concomitancia durativa. Un mismo sujeto lleva a cabo con voluntariedad dos acciones durativas distintas sobre un mismo objeto.

(19) a. E levantan[do] e feriendo en él, fagua tajadas delgadas (Enrique de Villena, Arte Cisoria, 1423, 88)

b. Y asiéndole del brazo le tornó a atar a la encina (Miguel de Cervantes, El ingenioso hidalgo don Quijote de la Mancha, 1605, 120)

6. Concomitancia puntual. Un sujeto realiza con voluntariedad dos acciones puntuales diferentes que inciden en un mismo objeto. Si interpretásemos que tanto la acción de sostener el cabo del hueso como el tajo que se hace requieren una mayor duración, podríamos encuadrarlo como un ejemplo de concomitancia durativa.

(20) Depués, teniendo el cabo del hueso con la yzquierda mano donde está la gordura çerca de la mano, fazer un tajo a raýz del hueso (Enrique de Villena, Arte Cisoria, 1423, 101)

7. Simultaneidad parcial con más duración de la subordinada. Los ejemplos que hemos recogido son de inclusión. En ambos intervienen dos sujetos en un lugar compartido. Las acciones de la subordinada y de la principal son durativas. La de la segunda comparte un segmento temporal de la primera.

(21) a. E Lamec andando a caça e su moço con él atravessava Caím de la una parte del monte a la otra por un sendero que vinié por esse monte (Alfonso X, General Estoria. Primera Parte, c. 1275, 18)

b. y estando así platicando con la lengua muy cerca los nuestros de los enemigos, que no había sino una puente quitada en medio, un viejo de ellos, allí a vista de todos, sacó de su mochila, muy despacio, ciertas cosas que comió (Hernán Cortés, Cartas de Relación, 1522, 231-232)

8. Coincidencia durativo-puntual. Hemos encontrado testimonios de límite inicial (22) -un sujeto realiza dos acciones: una durativa, la subordinada, y una puntual, la principal, que se produce al comienzo de la acción de la subordinada-, de inclusión (23) -un mismo sujeto lleva a cabo dos acciones: una puntual, expresada por la principal, que se produce durante el desarrollo de la subordinada, y otra durativa, la subordinada- y de límite final (24) -en (24a) un mismo sujeto lleva a cabo voluntariamente dos acciones: una puntual, expresada por la principal, que tiene lugar al final de la subordinada, y otra durativa, la subordinada; en (24b) son dos los sujetos-. 
(22) Comenzando, pues, a reinar, por tomar empresa conforme a su ánimo determinó de conquistar lo primero la ciudad e imperio de Constantinopla (Pedro Mejía, Silva de Varia Lección, 1540, 125)

(23) Et él, pensando en su fazienda et buscando arte por do escapase, miró a suso sobre sí (Anónimo, Calila e Dimna, 1251, 120)

que paseándose él también por un jardín oyó una voz que le decía Tolle, lege (Leopoldo Alas Clarín, La Regenta, 1884, 251)

(24) a. Acabando Moisén estos ruegos e esta oración e llorando toda vía grievemientre [...], paróse como triste por el pecado de los otros e la pena que ende levarién (Alfonso X, General Estoria. Primera Parte, c. 1275, 930)

b. Y llegando a un pueblo pequeñuelo, ya que salía el sol, vinieron los otros dos mensajeros llorando (Hernán Cortés, Cartas de Relación, 1520, 53)

9. Simultaneidad parcial con más duración de la principal. Los dos ejemplos son de inclusión. En (25a) diferentes sujetos realizan en un lugar compartido y con voluntariedad en la subordinada y sin ella en la principal dos acciones durativas. La subordinada, de menor duración, se produce durante el desarrollo de la principal; en (25b) un mismo sujeto lleva a cabo con voluntariedad ambas acciones.

(25) a. pasando el rey Juba por aquel mismo camino y con el mismo mozo, entre otros muchos que venían con el rey, el león estaba allí acaso muy cerca (Pedro Mejía, Silva de Varia Lección, 1540, 305)

b. $\quad$ y, sacando de las alforjas lo que en ellas había puesto, iba caminando y comiendo detrás de su amo muy de su espacio (Miguel de Cervantes, El ingenioso hidalgo don Quijote de la Mancha, 1605, 148)

Con las pruebas anteriores creemos haber demostrado que hay una amplia variedad de subtipos dentro de la simultaneidad expresada con gerundio. En concreto, hemos hallado los seis subtipos de simultaneidad total (sincronización durativa, sincronización puntual, coincidencia durativa, coincidencia puntual, concomitancia durativa y concomitancia puntual) y tres de los cuatro subtipos de simultaneidad parcial (simultaneidad parcial con más duración de la subordinada, simultaneidad parcial con más duración de la principal y coincidencia durativo-puntual). Además, en el caso de la simultaneidad parcial, se aprecia que en todos los casos el matiz que predomina en la oración subordinada es el 'durativo', que es el habitual, mientras que en la principal se emplean acciones o estados durativos o puntuales.

\subsection{El gerundio con significado no temporal}

El gerundio no solo se emplea con valores temporales. En latín ya presentaba usos modales e instrumentales (BASSOLS, 1945: §421). Los primeros no se perciben claramente en los autores arcaicos y clásicos, pero se documentan en etapas posteriores "concurriendo con los participios de presente" (26a), incluso alternando en algunas ocasiones en la misma oración (26b). A partir del siglo III el gerundio supera al participio de presente en frecuen- 
cia de uso. Los segundos, los instrumentales, se encuentran ya en el latín clásico (27). Aunque se sigue empleando con este valor en las etapas sucesivas, "en el latín decadente prevalece el significado modal".
a. quis talia fando temperet a lacrimis (Virgilio, La Eneida)
'quién hay que diciendo estas cosas pueda contener las lágrimas'
b. libero commeantes mare saepius adeundo ceteris incognitas terras (Quintus Curtius Rufus, De Rebus Gestis Alexandri Magni)
'navegando en mar abierto alcanzando más a menudo otras tierras desconocidas'

(27) hominis mens discendo alitur et cogitando (Cicerón, De Officiis)

'la mente del hombre se alimenta aprendiendo y pensando'

Sedano y Jiménez Juliá (2013: 90-91) hablan de un valor "vagamente temporal", relacionado con el instrumental, como en el ejemplo español se divierte rompiendo cosas por lo que del instrumental se derivaría el modal; es decir, 'se divierte con eso' $\rightarrow$ 'se divierte así’. Basándose en Lausberg (1966: §819.1), señalan que a partir del modal se producirían una serie de "interpretaciones causales, concesivas, condicionales".

A la vista de nuestros datos y recordando la regularidad del cambio semántico, es imposible esta evolución. Estamos de acuerdo en que lo instrumental y lo modal están relacionados, como se observa en latín (BASSOLS, 1945: §421) y seguimos constatando en romance, pero no se llega desde lo modal a lo casual (Viendo que no venían, se fueron), a lo concesivo (Aun lloviendo, iremos a la playa) o a lo condicional (Viniendo a la fiesta, podré perdonarle). En nuestra opinión, hay dos evoluciones:

1. Del ámbito temporal se pasa a otros más abstractos, como los de causa, concesión y condición.

2. Del ámbito no temporal se pasa al instrumento y al modo.

Aunque Bassols (1945: §421) analiza casos como los de (28) como gerundio instrumental, "casi siempre con un matiz causal y dependiendo de verbos que expresan una idea de cansancio o fatiga", creemos que es un cambio del gerundio temporal hacia el causal.

sum defessus quaeritando (Plauto, Amphitruo)

'estoy cansado de buscarlo'

La simultaneidad en ciertos contextos puede presentar matices causales, como en Viendo que no venían, se fueron, interpretable como 'al ver que no venían, se fueron' (RAE-ASALE, 2009: \$27.5a). Lo prospectivo puede adquirir un sentido concesivo (nos ponemos en el futuro cuando afirmamos que Aun lloviendo, iremos a la playa) o condicional (en Viniendo a la fiesta, podré perdonarle, la hipótesis nos lleva al futuro).

Cuando el gerundio no expresa tiempo, normalmente se emplea con valor instrumental. Al igual que ocurre con los sintagmas prepositivos de instrumento, se puede reinterpretar como modal: se divierte con eso 'se divierte así'. 
En resumen, con el gerundio se puede expresar el modo, el instrumento, la causa, la concesión y la condición.

\section{4. $E N+$ GERUNDIO}

En este apartado, en primer lugar, revisaremos las principales propuestas sobre el origen de $e n+$ gerundio y estableceremos nuestra propia hipótesis, en segundo lugar estudiaremos los valores temporales de esta construcción y, en tercer y último lugar, repasaremos los valores no temporales.

\subsection{Origen de $e n+$ gerundio}

La estructura en + gerundio ha sido objeto de debate tanto en lo que respecta a su origen como a los matices temporales que expresa. Desde el punto de vista diacrónico, Pato (2014: 834) ofrece una panorámica bastante amplia del estado de la cuestión en español y en otras lenguas romances:

En cuanto a su origen, la mayoría de los autores consultados defiende la continuación directa del sintagma latino IN + GERUNDIO > en + gerundio (Diez 1836-1844: 239, MeyerLübke 1899: 559-560, Cuervo 1953: 234, Gili Gaya 1964: 193, García de Diego 1970: 394, Muñío Valverde 1995: 119-21); otros, en cambio, consideran que es evolución independiente romance (Lyer 1934: 15). Lo cierto es que, salvo en rumano, el gerundio preposicional se documenta en todas las lenguas romances. El gérondif francés, por ejemplo, se forma con la preposición en y el participio presente (ver Halmóy 2003).

Por lo que respecta al español, las consideraciones más recientes sobre su uso apuntan al carácter "arcaico y popular" (Fernández Lagunilla 1999: 3470) y a que "ha caído prácticamente en desuso en la lengua estándar" (Penny 2006: 267) y "actual” (RAE/ASALE 2009: 2038).

En esta revisión bibliográfica falta la hipótesis de De los Mozos (1973: 128-134), quien sostiene que "en- $G$ es la transformación en gerundio de en-que-verbo personal" (29) y, por tanto, "la hipótesis latina (en-G = in-gerundio) es innecesaria". Este investigador realiza una amplia búsqueda de en que + verbo personal en textos medievales y clásicos, y llega a la conclusión de que salvo llegar, que es "el verbo más frecuente (todavía en español actual) en el sintagma en-G", los "lexemas predominantes son los mismos que también se reiteran construidos en en-G (en viendo, en oyendo, en sabiendo)".

(29) en que vio el agua toda fue alterada

en viendo el agua toda fue alterada

De los Mozos (1973: 134) se apoya en el argumento de que la preposición en "no sólo precede al gerundio sino también al infinitivo y al participio". También en que la estructura en que + verbo personal en otras lenguas y dialectos romances, como el aragonés (en que 
llegó) y su transformación en una forma no personal, el gerundio, en una lengua alejada de las romances como el vasco ${ }^{8}$, en la que "una forma personal del verbo puede llevar relativo $-n$ y sufijo de inesivo singular, es decir, -nean. El mismo sufijo, pero sin relativo $-n$ lleva una forma no personal, el inesivo singular del gerundio", mientras que "en romance una forma personal del verbo puede llevar que y la preposición en, es decir, en que. La misma preposición, pero sin que lleva una forma no personal: en-G".

De los Mozos (1973: 134) descarta la continuación directa del sintagma latino IN + gerundio:

La etimología latina de en-G, que Diez sugiere, Cuervo acepta y Meyer-Lübke ratifica, no puede apoyarse en una diferencia de denotación entre en- $G$ medieval y en-G clásico y actual. Los textos prueban que las dos denotaciones son sincrónicas desde las primeras documentaciones españolas. Dichas denotaciones son variantes contextuales o léxicas de un valor único [...] En-G expresa, frente a $G$, la acción verbal con su término, en tanto que $G$ indica la acción verbal no con su término, o con indiferencia al término.

IN + gerundio se documenta en latín "en los períodos arcaico y clásico" (BASSOLS, 1945: §421), por lo que algunos autores defienden su continuación en castellano con el significado "el tiempo durante el que se desarrollan los hechos o situaciones indicados por el verbo personal”, según Muñío (1995: 127 y 136), quien llega a dar la razón a De los Mozos:

Es más que probable que formalmente este sintagma sea un calco de in-G. El español naciente no necesita inventar una forma que ya posee la lengua de la que nace. Una vez adoptada, esa forma se resitúa en el sistema con valores, en este caso, no rigurosamente bien definidos y, por supuesto, no necesariamente idénticos a los latinos. En ese sentido es probable la tesis de De los Mozos.

La hipótesis sobre la procedencia latina de $e n+$ gerundio ha de plantearse con mucho cuidado. Es cierto que nuestros ejemplos de la General Estoria. Tercera Parte (30a-b) traducen IN + gerundio del texto de la Vulgata, pero esta no habría sido una estructura bien asentada en latín porque, salvo en gallego-portugués ${ }^{9}$, como observamos en las Cantigas de Alfonso X (31a), no existe en rumano ni en italiano ${ }^{10}$, y el catalán (31b), el francés (31c) y el occitano (31d) prefieren $e n+$ participio de presente.

\footnotetext{
${ }^{8}$ De los Mozos (1973: 129) recoge la propuesta de Pottier (1968: 149) para el francés: “En ce qu ill vint (a. fr. = en viniendo)", pero no ofrece testimonios.

9 En gallego esta expresión "indica anterioridad y no simultaneidad" (GÓMEZ PINTOR, 1984: 287).

10 "Si alguna vez se halla el gerundio precedido de la preposición in, debe considerarse esta como partícula expletiva" (BORDAS, 1852: 139).
} 
(30) a. Assí como la cibdat abierta e sin cerca de muros, así el varón que non puede tener su espíritu en fablando

sicut urbs patens et absque murorum ambitu ita vir qui non potest in loquendo cohibere spiritum suum (Alfonso X, General Estoria. Tercera Parte, a. 1280, 266) (Proverbios, XXIV, 28)

b. Las palabras son muchas a demás, e mucha vanidat an en departiendo verba sunt plurima multamque in disputandovanitatem habentia (Alfonso X, General Estoria. Tercera Parte, a. 1280, 385) (Eclesiastés, VI, 11)

(31) a. mas en dormindo a Madre de Deus direi-vos que lle fez (Alfonso X, A Madre do que livrou, apud Alvar y Beltrán Pepió (eds.) 1985: 423)

b. no.s podían partir, en anar ne en menjar, neen bevent ne en dormint (Anónimo, Història de Jacob Xalabin, c. 1400, CICA)

c. Je suis venu sur la terre pour subir la mort, pour mourir sur la croix, afin de sauver l'œuvre de mon Père qu'Adam avait condamnée en mangeant la pomme qu'Eve sa femme lui donna sur les conseils de l'Ennemi (Robert de Boron, Le Roman de l'Histoire du Graal, apud Micha (ed.) 1995: 27)

d. Farai un vers de dreyt nien / non er de mi ni d'autra gen, / non er d'amor ni de joven, / ni de ren au, / qu'enans fo trobatz en durmen / sus un chivau. (Guillermo IX de Aquitania, Canción IV, 1101-1126, apud Martínez Pérez 1987: 101-102).

En occitano existen ejemplos de en + participio de presente desde la segunda mitad del siglo XII, no solo como "gérondif prépositionnel devenu nom verbal" (32a), sino también como "gérondif prépositionnel" (32b), según testimonian los trovadores Faidit, Peguilhan, Maruelh o Berbezilh (JENSEN, 1994: 229). En gascón contemporáneo indica simultaneidad (ROMIEU Y BIANCHI, 2005: 346).
a. en mon viven (Faidit)
Malespina esta ferms en l'están (Peguilhan)
b. me levei en sezens, apres retorni m`en jazens (Maruelh)
qu`eissamenz creis com la lun`en creissenz (Berbezilh)

Dado que los primeros testimonios en castellano nos llevan al siglo XIII, podemos pensar que esta construcción puede ser un contagio de la estructura franca. Para comprobarlo, hemos realizado una búsqueda en el CORDE con los verbos salir y entrar (33), y hemos hallado en el siglo XIII 9 casos de en saliendo y 1 caso de en entrando:

(33) Et en saliendo un día a buscar qué comiesen, dexó sus fijos en el soto (Anónimo, Calila e Dimna, 1251, CORDE)

\&en saliendo en el de su palacio; parossele delante una bibda (Alfonso X, Estoria de Espanna que fizo el muy noble rey don Alfonsso, c. 1270, CORDE)

e en saliendo ellos que mató Dios en los egipcianos todos los primeros fijos (Alfonso X, General Estoria. Primera Parte, 1275, CORDE)

\& en saliendo cayo le vna corona sobre la cabeça (Anónimo, Castigos, 1293, CORDE) E balian / en entrando en Nazaret / oyo fazer muy grandes / duelos por toda la uilla (Anónimo, Gran Conquista de Ultramar, 1293, CORDE)

$\mathrm{Y}$ en saliendo el otro de casa, puso la mano a la espada y diole un golpe en la cabeça y matolo (Anónimo, Libro del Caballero Zifar, 1300-1305, CORDE) 
Entre las obras que recogen esta construcción se encuentran el Calila e Dimna, la Gran Conquista de Ultramar y el Libro del Caballero Zifar, obras que presentan rasgos ultrapirenaicos. Respecto a la producción de Alfonso X El Sabio, como la General Estoria (12701280) o la Estoria de Espanna (1270-1284), es bien sabido que en su elaboración intervinieron colaboradores provenzales (FERNÁNDEZ-ORDÓÑEZ, 2005: 403). Finalmente, los Castigos nos han llegado a través de varios manuscritos, por lo que resulta muy complicado determinar la procedencia de sus autores.

El influjo franco en la etapa prealfonsí fue primordial no solo en los textos literarios, sino también en los no literarios (ECHENIQUE ELIZONDO y SÁNCHEZ MÉNDEZ, 2005: 319 y 373-374). Un acontecimiento cultural que motivó su llegada desde el siglo XII fueron las peregrinaciones a Santiago de Compostela, por lo que su presencia fue constante en este periodo, que pudo influir en el trasvase de expresiones francas al castellano, entre las que se encontraría en + gerundio.

Creemos que el castellano refleja todas las posibilidades apuntadas, algunas más transparentes en ciertos tipos de textos o registros que otras:

a) Una herencia latina, ya que en latín arcaico y clásico IN podía preceder al gerundio (BASSOLS, 1945: §421) y en latín vulgar "se hizo frecuente su uso precedido de alguna preposición”, entre ellas IN (GÓMEZ PINTOR, 1984: 287).

b) Un origen autóctono del romance peninsular, como defiende De los Mozos (1973: 128-134).

c) Un contagio de la estructura franca en + participio de presente, cuya forma a veces muestra en posición final una nasal tras la pérdida de la dental sorda final (estant $>$ están, como en (31c-d)) o la consonante dental sonorizada (estant > estand, fácilmente interpretable como estando).

\section{2. $E n+$ gerundio con significado temporal de simultaneidad}

En lo que respecta a los significados de $e n+$ gerundio, podemos partir de la síntesis que ofrece Pato (2014: 835-836):

El significado temporal de en + gerundio en español moderno, según Gili Gaya (1964: 193), Seco (1988: 227) y la Nueva gramática de la lengua española (NGRAE) (RAE/ASALE 2009: 518 y 2064), es el de 'anterioridad inmediata' (en acabando de comer, saldré contigo 'cuando haya comido') [...] Por extensión, el gerundio preposicional también puede expresar 'simultaneidad', es decir, coincidencia temporal (Pablo habla en durmiendo) o coincidencia en el desarrollo de dos acciones (en pasando, oyeron voces en aquella casa 'a la vez que') [...] En + gerundio sirve también para expresar la noción de puntualidad (en nasçiendo 'en el punto que nació') [...]. Se suele admitir [...] el uso del gerundio con valor de 'posterioridad inmediata' (en acabando su ejercicio 'inmediatamente después de') [...] De hecho, hoy en día la NGRAE sostiene que, en la mayoría de los casos, el gerundio preposicional expresa 'posterioridad inmediata' (RAE/ASALE 2009: 2063). En el fondo, se trata de emplear una 'nueva' terminología, y unificar el tratamiento con otras oraciones temporales. 
La mayoría de los investigadores, empezando por Cuervo (1953: 234-36) y siguiendo por otros que repiten su opinión, como Hanssen (1913: 261), Gili Gaya (1964: 197), García de Diego (1970: 394), Muñío (1995: 119) y Pawlik (2010: 43), establece una división hasta el siglo XV, periodo en el que en + gerundio expresa 'simultaneidad', ya que a partir del XVI se impone el significado de 'anterioridad inmediata'. De los Mozos (1995: 73-117) no comparte esta idea y cree que "las denotaciones de anterioridad inmediata y de simultaneidad, que son sincrónicas, no constituyen el valor de $e n-G$. Son denotaciones léxicas o contextuales, sentidos diversos de un valor único, siempre el mismo desde los primeros textos" (34).

E en estando comprando un faisán, llegó a él un ome malo (Anónimo, Libro del Caballero Zifar, 1300-1305, apud De los Mozos, 1973, 113)

Este investigador parte de la distinción que realiza Ruipérez (1954: 84) entre los semantemas transformativos y no transformativos y lo aplica a la construcción en + gerundio: "en los lexemas no transformativos el valor puntual (provisionalmente establecido) se realiza con sentido initivo (en sudando); en los lexemas transformativos, con sentido finitivo (en muriendo)". Esta estructura vendría a ocupar un hueco vacío en nuestra lengua, ya que, a diferencia de la oposición cantaba 'duración' / cantó 'puntualidad', el español no presentaba este doblete para el gerundio, que expresa únicamente 'duración'. De este modo, con el matiz 'puntual' de en + gerundio quedaría establecida esta nueva oposición, lo que permitiría la expresión de la coincidencia, como defienden Caro (1945: 38) o Llorente (1947: 168).

De los Mozos (1973: 116) ofrece algunos ejemplos de coincidencia (35), pero creemos que no son idénticos. En (35c) la puntualidad de la acción de la subordinada es clara, de modo que estaríamos ante un testimonio de coincidencia puntual, ya que un mismo sujeto realiza sin voluntariedad dos acciones puntuales distintas. En cambio, en (35a-b) y (35d) se marca el término de una acción durativa (cantar) con el verbo acabar, de modo que, según nuestra propuesta, serían tres ejemplos de coincidencia durativo-puntual final, dado que un mismo sujeto lleva a cabo, en (35b) y (35d) voluntariamente y en (35a) con voluntariedad en la subordinada y sin ella en la principal, dos acciones: una puntual, la principal, que tiene lugar al final de la subordinada, y otra durativa, la subordinada.

(35) a. en acabando el pastor su canto, descubrió los que con los ramos venían

b. en acabando el canto Galatea, llegó adonde Florisa estaba

c. en oyendo Silerio su voz, le conoció

d. en acabando el canto, acabó el camino

Defendemos parcialmente la idea de atribuir el matiz 'puntual' a la acción de la subordinada, ya que creemos que en (35a-b) y (35d) se trataría más bien del momento final de una acción durativa, cantar, que viene marcado por el verbo acabar. Creemos que la oposición cantaba 'duración' / cantó 'puntualidad' debería ser más bien cantaba 'imperfectivo' I cantó 'perfectivo', dado que esta palabra implica necesariamente un desarrollo. En (35c) Silerio reconoce a la persona que habla justo al escucharla, por lo que la instantaneidad de oír impide establecer su inicio. 
Muñío (1995: 136) explica el problema fundamental de la tesis de De los Mozos sobre el significado temporal de en + gerundio y recoge un testimonio latino con su traducción romance que presenta matiz 'durativo', es decir, de "proceso sin su término", que equivaldría a 'mientras siembra', 'durante la siembra' (36):

Los dos valores que se le asignan son, pues, el de simultaneidad y el de anterioridad inmediata, pero según De los Mozos, como realizaciones de un valor único, proceso con su término, concepto ambiguo donde los haya, ambigüedad que aumenta al añadir al concepto término los adjetivos inicial y final. Porque los conceptos de proceso, término, inicial, final vienen a depender, en última instancia, no solamente del lexema del gerundio en cuestión, sino muy a menudo del lexema del verbo personal y del tiempo en que éste aparece en el discurso combinado con enG.

(36) Escuchat: Salio un ombre a sembrar. En sembrando lo uno cayo cabo la carrera (Anónimo, El Nuevo Testamento, según el Manuscrito Escurialense I.I-6, 1260)

Audite: ecce exiit seminans ad seminandum. El dum seminat aliud cecidit circa viam (Jerónimo de Estridón, Vulgata, 382)

Para Muñío (1995: 137), "si algo produce la "impresión” de que en este caso en sembrando tiene el valor del proceso con su término, no es la preposición en, sino el tiempo del verbo personal. Sustitúyase cayó por caía: «en sembrando lo uno caía cabo la carrera»". Incluye más testimonios (37), que pueden ponerse en relación con distintas versiones de la $B i$ blia. En (37a) y (37c) un mismo sujeto realiza, con voluntariedad en la subordinada y sin ella en la principal, dos acciones: una puntual, expresada por la principal, que tiene lugar durante el desarrollo de la subordinada, y otra durativa, la subordinada. En (37b) un mismo sujeto realiza voluntariamente las acciones de la principal y de la subordinada, ambas durativas. La principal, de menor duración, se produce durante el desarrollo de la subordinada. En (37a) y (37c) estaríamos ante dos testimonios de coincidencia durativo-puntual de inclusión y el ejemplo (37b) sería de simultaneidad parcial con más duración de la subordinada de inclusión.

a. En faziendo oracion, camios la semeiança de su cara e fue uestido de blando e resplandecient (Anónimo, El Nuevo Testamento, según el Manuscrito Escurialense I.I-6, 1260)

Et facta est, dumoraret, species vultus eius altera; et vestitus eius albus et refulgens (Jerónimo de Estridón, Vulgata, 382)

b. En yendo se pora Iherusalem, pasaua por medio de Samaria e Galilea (Anónimo, El Nuevo Testamento, según el Manuscrito Escurialense I.I-6, 1260)

Dum iret in Ierusalem (Jerónimo de Estridón, Vulgata, 382)

c. E en yendo se fueron sanos (Anónimo, El Nuevo Testamento, según el Manuscrito Escurialense I.I-6, 1260)

Dum irent, mundati sunt (Jerónimo de Estridón, Vulgata, 382)

Otro valor que, según él, ofrece es el de simultaneidad absoluta. Para nosotros, coincidencia puntual, dado que un mismo sujeto realiza sin voluntariedad en la principal y con ella en la subordinada dos acciones puntuales distintas. Este matiz 'puntual' se debe a SIMUL 'a la vez', 'al mismo tiempo': "una acción no puede darse sin que se dé otra a la 
vez", es decir, "las dos acciones empiezan y acaban a la vez, esto es SIMUL, de vuelta" (MUÑ̃́O, 1995: 137-138) (recuérdese que las expresiones medievales de vuelta o de manbuelta significan 'conjuntamente', 'a la vez') (38).

(38) ¿Quieres que lo vayamos a coger? Diz: No, ca por uentura en cogiendo el ballico no arranquedes el trigo de vuelta (Anónimo, El Nuevo Testamento, según el Manuscrito Escurialense I.I-6, 1260)

"Vis, imus, et colligimus ea? Et ait: ne forte colligentes zizania, eradicetis simul cum eis et triticum (Jerónimo de Estridón, Vulgata, 382)

En otros ejemplos "la acción del gerundio está ya en proceso de desarrollo cuando se produce la del personal" y "puede cesar nada más producirse ésta" (MUÑíO, 1995: 140) (39). Al coincidir el instante en el que entra el conde Rubén y las otras dos personas dejan de hablar, interpretamos que se trataría de un testimonio de coincidencia durativo-puntual final, ya que diferentes sujetos llevan a cabo con voluntariedad dos acciones: una puntual, expresada por la principal, que tiene lugar al final de la subordinada, y otra durativa, que es la subordinada. Si hubieran seguido conversando los sujetos de la subordinada, hablaríamos de coincidencia durativo-puntual de inclusión, en la que la acción principal tendría lugar durante el desarrollo de la subordinada.

(39) E quando llego Roboan asentose delante ella e començaron a fablar muchas de las cosas. E en fablando entro el conde Ruben, tio de la infante, e Roboan se leuanto a el (Anónimo, Libro del Caballero Zifar, 1300-1305)

Exiten otros casos en los que "no siempre está claro que el comienzo del proceso marcado por en $G$ sea anterior al del marcado por el verbo personal" (MUÑíO, 1995: 140), por lo que existiría vacilación entre una interpretación de anteriodidad inmediata o de simultaneidad. Según Muñío, "el valor de en $G$ no depende solamente de la preposición en y del lexema del gerundio, sino, conjuntamente con ellos, del lexema y del tiempo del verbo conjugado con el que entra en relación" (MUÑíO, 1995: 140) (40). Su propuesta es la siguiente:

Si éste [el tiempo conjugado] es terminativo, perfectivo, coincide solamente en un punto del desarrollo de en $G$ que viene produciéndose y que, o deja de producirse entonces o sigue produciéndose [...] En cambio, si el tiempo del verbo personal es no terminativo, imperfectivo, con frecuencia es difícil precisar si el comienzo de en $G$ es anterior al inicio del verbo personal, o por el contrario el comienzo y el desarrollo de las dos acciones es simultáneo desde el comienzo; dependerá de los lexemas de los dos verbos y del contexto. Generalmente se trata de desarrollos simultáneos en todo el proceso, mientras.

(40) a. et en yendo por la carrera pensando mucho en el fecho de la batalla que auie de auer, adormeciosse (Alfonso X, Crónica General I, c. 1270)

b. et assi commo las yua tomando, matávalas et sacávalas de la red, et en matando las perdizes, dával el viento en los ojos tan de reçio quel fazía llorar (Don Juan Manuel, El Conde Lucanor, 1330-1335, 63) 
El testimonio (40a) sería de coincidencia durativo-puntual de inclusión (simultaneidad parcial), dado que un mismo realiza dos acciones: una puntual, expresada por la principal, que tiene lugar durante el desarrollo de la subordinada, y otra durativa, la subordinada. En (40b), que encontramos en nuestro corpus y que recogemos en (43b), estaríamos ante un ejemplo de coincidencia durativa (simultaneidad total), puesto que un mismo sujeto lleva a cabo sin voluntariedad en la principal y con ella en la subordinada dos acciones durativas distintas.

Aunque estamos de acuerdo en los subtipos de simultaneidad de Muñío (1995: 136142) y Pato (2014: 835-836) de en + gerundio, creemos que existen más: sincronización durativa (41), sincronización puntual (42), coincidencia durativa (43), coincidencia puntual (44), simultaneidad parcial con más duración de la subordinada (45), coincidencia durativo-puntual (46-48) y simultaneidad parcial con más duración de la principal (49).

1. Sincronización durativa. Un mismo sujeto realiza con voluntariedad dos acciones durativas.

(41) Et en viviendo con los otros lobos çervales et con las gulpejas, non fazía lo que ellos fazían, nin robava (Anónimo, Calila e Dimna, 1251, 306)

2. Sincronización puntual. En (42a) diferentes sujetos llevan a cabo dos acciones puntuales distintas en un lugar compartido. En (42b) solo hay un sujeto.

(42) a. e en saliendo ellos que mató Dios en los egipcianos todos los primeros fijos (Alfonso X, General Estoria. Primera Parte, c. 1275, 515)

b. En llegándose a juntar se saludaron cortésmente (Miguel de Cervantes, El ingenioso hidalgo don Quijote de la Mancha, 1605, 181)

3. Coincidencia durativa. En (43a) un mismo sujeto realiza sin voluntariedad en la principal y con ella en la subordinada dos acciones durativas distintas. En (43b) los sujetos son diferentes.

(43) a. Assí como la cibdat abierta e sin cerca de muros, así el varón que non puede tener su espíritu en fablando

sicut urbs patens et absque murorum ambitu ita vir qui non potest in loquendo cohibere spiritum suum (Alfonso X, General Estoria. Tercera Parte, a. 1280, 266) (Proverbios, XXIV, 28)

b. et en matando las perdizes, daval el viento en los ojos (Don Juan Manuel, El Conde Lucanor, 1330-1335, 116)

4. Coincidencia puntual. En (44a) un mismo sujeto lleva a cabo sin voluntariedad en la principal y con ella en la subordinada dos acciones puntuales distintas. En (44b) son diferentes los sujetos. 
(44) a. Et en abriendo la boca para fablar, cayó en tierra et murió (Anónimo, Calila e Dimna, 1251, 165)

b. En saliendo del mismo la goleta Cartaginesa, quedarán completamente paralizadas las obras en aquel magnífico arsenal (El Heraldo, 6/03/1852, 2)

5. Simultaneidad parcial con más duración de la subordinada. Únicamente hemos documentado un ejemplo de límite final (45), en el que un mismo sujeto lleva a cabo sin voluntariedad en la principal y con ella en la subordinada dos acciones durativas. La principal, de menor duración, se produce al final de la subordinada.

(45) y comenzaron luego a dar muy grandes alaridos, haciendo muchas ahumadas, tirándonos con hondas y sin ellas muchas piedras y flechas y varias; por manera que en llegándonos cerca recibíamos mucho daño (Hernán Cortés, Cartas de Relación, 1520, 184)

6. Coincidencia durativo-puntual. Hemos hallado testimonios de límite inicial (46) un mismo sujeto realiza con voluntariedad dos acciones: una puntual, expresada por la principal, que se produce al comienzo de la subordinada, y esta, que es durativa-, de inclusión (47) —en (47a) diferentes sujetos y en (47b) el mismo sujeto realizan dos acciones: una puntual, expresada por la principal, que se produce durante el desarrollo de la subordinada, y otra durativa, la subordinada; en (47a) el sujeto actúa sin voluntariedad en la principal y con ella en la subordinada, mientras que en (47b) actúa con voluntariedad en ambas- y de límite final (48) —en (48a) diferentes sujetos y en (48b) uno solo llevan a cabo dos acciones: una puntual, la principal, que tiene lugar al final de la subordinada, y otra durativa, la subordinada; en (48a) los sujetos actúan con voluntariedad y en (48b) con ella en la subordinada y sin ella en la principal-.

(46) y en saliendo a ellos, envié muy delante ciertos de caballo y algunos peones (Hernán Cortés, Cartas de Relación, 1526, 355)

(47) a. Et en levándolo a justiçiar, encontrólos el religioso (Anónimo, Calila e Dimna, 1251, 141)

b. et en riendo, dio con la mano en su fruente (Don Juan Manuel, El Conde Lucanor, 1330-1335, 82)

(48) a. et en llegando a la puerta, saliólo a resçebi el can con grant gozo (Anónimo, Calila e Dimna, 1251, 266)

b. Et en llegando al marido falló ý al çarapico (Anónimo, Calila e Dimna, 1251, 342)

7. Simultaneidad parcial con más duración de la principal. Solo obtuvimos un caso de inclusión (49), en el que diferentes sujetos realizan con voluntariedad en la subordinada y sin ella en la principal ambas acciones durativas. La subordinada, de menor duración, se produce durante el desarrollo de la principal. 
(49) Et en pasando por allí llevando el cuerpo [a ente]rrar, estaba aquel mançebo asentado en los poyos de la puert[a de la] çibdat (Anónimo, Calila e Dimna, 1251, 329)

Con esta exposición de posibilidades creemos haber demostrado que existe una amplia variedad de subtipos dentro de la simultaneidad con $e n+$ gerundio. Compartimos la idea de De los Mozos (1973: 112) de que "las denotaciones de anterioridad inmediata y de simultaneidad [...] son sincrónicas". Del mismo modo que desde el siglo XIII recoge testimonios de anterioridad inmediata, defendemos que el valor de simultaneidad se prolonga, al menos, hasta el siglo XIX, aunque desde el XVI predomine la anterioridad inmediata sobre la simultaneidad.

Basándonos en testimonios de las fuentes documentales citadas al final del trabajo, consideramos que el valor de acción verbal con su término que atribuye De los Mozos (1973: 112) a en + gerundio no es del todo preciso. En un ejemplo de simultaneidad total (38) o en uno de simultaneidad parcial (47b), la acción de la subordinada con en + gerundio se interpreta como un proceso sin su término. En otros casos, como (48), el límite final de la acción de la subordinada viene determinado por el verbo llegar, mientras que en (46) el verbo salir marca el inicio de la acción.

En resumen, hemos hallado testimonios de cuatro de los seis subtipos de simultaneidad total (sincronización durativa, sincronización puntual, coincidencia durativa y coincidencia puntual) y tres de os cuatro subtipos de simultaneidad parcial (simultaneidad parcial con más duración de la subordinada, coincidencia durativo-puntual y simultaneidad parcial con más duración de la principal). Además, como en el gerundio, en la simultaneidad parcial se aprecia que en todos los casos el matiz que predomina en la oración subordinada es el 'durativo', que es el habitual, mientras que en la principal se emplean acciones o estados durativos o puntuales.

\section{3. $E n+$ gerundio con significado no temporal}

Como el gerundio sin preposición, el preposicional también presenta usos no temporales. Muñío (1995: 132-134) rebate a De los Mozos (1973: 70) cuando afirma que en + gerundio siempre tiene valor temporal, ya que recoge testimonios en los que cabría una interpretación distinta. Menciona cuatro: el medio o instrumento, el modal, el condicional y el concesivo. En algunos casos Muñío sostiene que "en $G$ se acerca más al valor de medio, instrumento" (50a). Otros pasajes muestran el modo en que se realiza la acción expresada por el verbo personal (50b). En otros, "el sentido modal es más general e impreciso y puede, incluso, coexistir con el temporal" (50c). En ocasiones, "parece prevalecer la denotación condicional, aunque también intervienen matices temporales", pero son usos esporádicos (50d). En otros ejemplos "en $G$ aporta con bastante claridad denotaciones o valores concesivos" (50e). 
(50) a. Dixo el rey: —Pues ¿qué tienes por bien? Dixo: —Que te aconsejes, que el rey que se aconseja vençe en aconsejándose con los entendidos et con los leales de su casa, más que otro rey con sus mesnadas et con su grand poder (Anónimo, Calila e Dimna, 1251)

b. Et porend, los de la tierra de Occident, alli o la fallan la suelen colgar alos ninnos alos cuellos, por que les non faga el uino mal, et se criassen meior et más ayna en beuiendolo (Alfonso X, Lapidario, 1250)

c. E el luego quel uio, descendio del cauallo et parosse sobrel mui triste, et dixol en llorando (Alfonso X, Crónica General II, 1270-1284)

d. et por end es bona pora las postemas calientes, et sennaladamiente a aquella que llaman carbonclo, ca en esfriando las mucho, arriedra que no se faga postema. Et si la fazen poluos, et los traen sobre las encias, sana las cauaduras que son en ellas (Alfonso X, Lapidario, 1250)

e. Et llegaron se y trezientos et diez et ocho obispos; e estando alli delante ell emperador Costantino [...] començaron los obispos a querellarse le ell uno dell otro de los tuertos que se fazien en seyendo uezinos (Alfonso X, Crónica General I, c. 1270)

Como en los usos no temporales del gerundio, hay dos evoluciones:

1. Del ámbito de lo temporal se pasa a otros más abstractos, como los de causa, concesión y condición,

2. Del ámbito no temporal se pasa al instrumento y al modo. También en estos casos, del instrumento se puede evolucionar al modo, como se observa en (50b).

En resumen, como en el caso del gerundio, con en + gerundio se puede expresar el modo, el instrumento, la causa, la concesión y la condición.

\section{CONCLUSIONES}

El estudio que hemos llevado a cabo sobre el gerundio y la construcción en + gerundio y sus valores temporales y no temporales permite extraer una serie de conclusiones:

En primer lugar, el gerundio castellano procede de la confluencia del gerundio y del participio de presente latinos, pero su uso no se generaliza hasta el siglo XV, momento en el que decae el empleo del participio de presente.

En segundo lugar, el gerundio expresa los seis subtipos de simultaneidad total (sincronización durativa, sincronización puntual, coincidencia durativa, coincidencia puntual, concomitancia durativa y concomitancia puntual) y tres de los cuatro subtipos de simultaneidad parcial (simultaneidad parcial con más duración de la subordinada, simultaneidad parcial con más duración de la principal y coincidencia durativo-puntual). En cambio, la construcción en + gerundio expresa cuatro subtipos de simultaneidad total (sincronización durativa, sincronización puntual, coincidencia durativa y coincidencia puntual) y tres de simultaneidad parcial (simultaneidad parcial con más duración de la subordinada, coincidencia durativo-puntual y simultaneidad parcial con más duración de la principal). Por 
tanto, la construcción con preposición ofrece menos valores que la del gerundio sin ella. Le faltan los de la concomitancia durativa y puntual.

En tercer lugar, el empleo en español de $e n+$ gerundio puede tener una triple causa: una herencia latina, un origen autóctono del romance peninsular y un contagio de la estructura franca en + participio de presente, que, por razones fonéticas, pudo interpretarse como gerundio (por ejemplo, estant > estand 'estando').

Por último, tanto el gerundio como en + gerundio pueden expresar los valores no temporales de modo, instrumento, causa, concesión y condición. En ambas hay dos evoluciones semánticas: por un lado, del ámbito de lo temporal se pasa a otros más abstractos, como los de causa, concesión y condición, y, por otro, del ámbito no temporal se pasa al instrumento y al modo.

\section{BIBLIOGRAFÍA}

Alvar, Carlos. y Beltrán Pepió, Vicente (1985): Antologâia de la poesâia gallego-portuguesa, Madrid, Alhambra.

Bassols De Climent, Mariano (1956/1987): Sintaxis latina. 1, Madrid, Consejo Superior de Investigaciones Científicas.

BorDAs, LuIs (1852): Gramàtica italiana, Barcelona, Imprenta y Librería de D. Manuel Saurí.

Caro, Miguel Ángel (1945): Tratado del participio. Obras Completas, Tomo 5, Bogotá, Instituto Caro y Cuervo.

Cuervo, Rufino José (1953): Diccionario de Construcción y Régimen de la lengua castellana, Bogotá, Instituto Caro y Cuervo.

DE los Mozos, Santiago (1973): El gerundio preposicional, Salamanca, Universidad de Salamanca.

DiEZ, FrIEDRICH (1836-1844): Grammatik der romanischen Sprachen, Bonn, Weber.

Echenique Elizondo, María Teresa y Sánchez Méndez, Juan (2005): Las lenguas de un reino: historia lingüística hispánica, Madrid, Gredos.

Fernández Lagunilla, Marina (1999): "Las construcciones de gerundio", en Bosque, Ignacio y Demonte, Violeta (dirs.), Gramática descriptiva de la lengua española, 2, Madrid, Espasa Calpe, 3443-3506.

FernándeZ-OrdóñeZ, Inés (2005): “Alfonso X el Sabio en la historia del español”, en Cano Aguilar, Rafael (coord.), Historia de la lengua española, Barcelona, Ariel, 381-422.

García de Diego, Vicente (1970): Gramática histórica española, Madrid, Gredos.

Gili Gaya, SAmuel (1964): Curso superior de sintaxis española, Barcelona, Bibliograf.

Goméz Pintor, María Dolores (1984): "Usos y valores de la preposición en en Merlín e familia de Alvaro Cunqueiro", Verba, 11, 281-287.

Halmøy, Odile (2003): Le gérondif en français, Gap/París, Ophrys.

Hanssen, Federico (1913): Gramática histórica de la lengua castellana, París, Les Marais.

Jensen, Frede (1994): Syntaxe de l'ancien Occitan, Tübingen, Niemeyer.

LAusberg, Heinrich (1966): Lingüística Románica, Madrid, Gredos.

Llorente, ANOTNio (1947): Estudio sobre el habla de La Ribera, Salamanca, CSIC.

Lyer, Stanislav (1934) : Syntaxe du gérondif et du participe présent dans les langues romanes, París, Librairie E. Droz.

MARTínez PÉREZ, ANTONIA (1987) : La poesía medieval francesa del «non-sens » : fatrasie y géneros análogos, Murcia: EDITUM. Ediciones de la Universidad de Murcia. 
Meyer-LüBKe, Wilhelm (1899): Grammatik der romanischen Sprachen, III, Leipzig, O. R. Reisland. Micha, Alexandre (tr.) (1995): Le roman de l'histoire du Graal, Paris, Honoré Champion.

Mora García, JAVIER (2016): Las expresiones de simultaneidad en español y en otras lenguas europeas, con atención especial a la situación en los siglos XVIII y XIX, Valladolid, Universidad de Valladolid.

MuÑío Valverde, José Luis (1995): El gerundio en el español medieval (siglos XII-XIV), Málaga, Agora.

PAWLIK, JANUSZ (2010): "Formas no personales del verbo en el español medieval", Studia Romanica Posnaniensia, 37:2, 39-46.

Pato Maldonado, Enrique (2014): “En llegando los datos la intuición se matiza. El gerundio preposicional en la historia de la lengua española", RILCE: Revista de Filología Hispánica, 30:3, 833-860.

Penny, Ralph (1993/2006): Gramática histórica del español, Barcelona, Ariel.

PotTier, Bernard (1968): Lingüística moderna y filología hispánica, Madrid, Gredos.

Real Academia De la lengua Española Y Asociación De Academias De la lengua Española (2009): Nueva gramática de la lengua española, Madrid, Espasa.

Real Academia Española: Corpus Diacrónico del Español [Online]. Accesible en: http://www.rae. es [Consultado 10 marzo 2017].

Romieu, Maurice Y BiAnchi, André (2005): Gramatica de l'occitan gascon contemporanèu, Pessac, Presses universitaires de Bordeaux.

SÁnchez Ruipérez, Martín (1954): El sistema de tiempos y aspectos del verbo griego antiguo. Análisis funcional sincrónico, Salamanca, Universidad de Salamanca-Consejo Superior de Investigaciones Científicas.

Seco, Manuel (1988): Diccionario de dudas y dificultades de la lengua española, Madrid, Espasa-Calpe.

Sedano, Mercedes Y Jiménez Juliá, Tomás Eduardo (2013): "El gerundio en español: origen, usos y normas", Español actual: Revista de español vivo, 100, 87-130.

Torruella, Joan (dir.), junt amb Pérez Saldanya, Manel i Martines, Josep (2009): Corpus Informatitzat del Català Antic [Online]. Accesible en: http://lexicon.uab.cat/cica, [Consultado 10 marzo 2017].

\section{FUENTES DOCUMENTALES}

[CALILA] Calila e Dimna, edición, introducción y notas de Juan Manuel Cacho Blecua y María Jesús Lacarra. Madrid: Castalia, 1988.

[CISORIA] Enrique de Villena, Arte cisoria, edición y estudio de Russell V. Browm, Barcelona: Humanitas, 1984.

[GEI] Alfonso X El Sabio, General Estoria. Primera parte, edición de Pedro Sánchez-Prieto Borja. Madrid: Fundación José Antonio de Castro, D. L., 2009.

[GEIII] Alfonso X El Sabio, General Estoria. Tercera parte. IV, Libros de Salomón: Cantar de los Cantares, Proverbios, Sabiduría y Eclesiastés, edición de Pedro Sánchez-Prieto Borja y Bautista Horcajada Diezma. Madrid: Gredos, 1994.

[HERALDO] El Heraldo (1/03/1852-13/03/1852), 3.011-3.022, en Hemeroteca Digital [Online]. Accesible en: http://hemerotecadigital.bne.es/index.vm [Consultado 10 julio 2015].

[LUCANOR] Don Juan Manuel, El Conde Lucanor, en Obras completas. II, edición, prólogo y notas de José Manuel Blecua. Madrid: Gredos, D. L., 1983.

[QUIJOTE] Miguel de Cervantes, El ingenioso hidalgo don Quijote de la Mancha. 1, edición de J. J. Allen. Madrid: Cátedra, 1994. 
[REGENTA] Leopoldo Alas, La Regenta. 1, edición de Juan Oleza; con la colaboración de Josep Lluis Sierra y Manuel Diago. Madrid: Cátedra, 1987.

[RELACIÓN] Cartas de relación: Informes al emperador Carlos V sobre la conquista de México; Ordenanzas de gobierno de la Nueva España, edición de Mario Hernández Sánchez-Barba. Madrid: Fundación José Antonio de Castro, 2013.

[SILVA] Pedro Mexía, Silva de varia lección, edición de Isaías Lerner. Madrid: Castalia, 2003. 
